\title{
Prevalence of psychoactive substances, alcohol and illicit drugs, in Spanish drivers: A roadside study in $\mathbf{2 0 1 5}$
}

Antonia Domingo-Salvany ${ }^{a t}, M$ Jesús Herrero ${ }^{b}, B^{\prime}$ Beatriz Fernandez ${ }^{c}$, Julio Perez ${ }^{d}$, Pilar del Real ${ }^{d}$, Juan Carlos González-Luqued, Rafael de la Torre ${ }^{\mathrm{e}}$.

a Drug Abuse Epidemiology Research Group, Institut Hospital del Mar d'Investigacions Mèdiques de Barcelona - IMIM. Doctor Aiguader 88. E-08003 Barcelona, Spain. adomingo@imim.es

${ }^{\mathrm{b}}$ Reumathology Service. Parc de Salut Mar.

cLaboratorio Echevarne. Provença 312, bajos. E-08037 Barcelona, Spain. bfernandez@echevarne.com

d Directorate General for Traffic. Josefa Valcarcel 44. E-28071. Madrid, Spain. jperezpaz@dgt.es, pdelreal@dgt.es, jcluque@dgt.es

e Integrative Pharmacology and Systems Neurosciences Research Group, Institut Hospital del Mar de Investigacions Mèdiques - IMIM, Barcelona, Spain. rtorre@imim.es

+ Corresponding author:

Antonia Domingo-Salvany,

IMIM-Hospital del Mar Medical Research Institute

Dr. Aiguader, 88,E- 08003. Barcelona, Spain.

Tel: +34 933160757,

Fax: +34 933160797,

e-mail: adomingo@imim.es 


\section{Prevalence of psychoactive substances, alcohol and illicit drugs, in Spanish drivers:}

\section{A roadside study in 2015}

\section{ABSTRACT}

A survey was conducted during 2015 to monitor psychoactive substance use in a sample of drivers in Spanish roads and cities. Traffic police officers recruited drivers at sites carefully chosen to achieve representativeness of the driver population. A brief questionnaire included the date, time, and personal and driving patterns data. Alcohol use was ascertained through ethanol breath test at the roadside and considered positive if concentrations $>0.05 \mathrm{mg}$ alcohol/L were detected. Four drug classes were assessed onsite through an oral fluid screening test that, if positive, was confirmed through a second oral fluid sample at a reference laboratory. Laboratory confirmation analyses screened for 26 psychoactive substances. To evaluate the association between drug findings and age, sex, road type (urban/interurban), and period of the week (weekdays, weeknights, weekend days, weekend nights), logistic regression analyses were done (overall, and separately for alcohol, cannabis and cocaine).

A total of 2744 drivers, mean age of 37.5 years, $77.8 \%$ men, were included. Overall, $11.6 \%$ of the drivers had at least one positive finding to the substances assessed. Substances more frequently testing positive were cannabis $(7.5 \%)$, cocaine $(4.7 \%)$ and alcohol $(2.6 \%)$. More than one substance was detected in $4 \%$ of the subjects. The proportion of positive results decreased with age, and was more likely among men and on urban roads. The pattern for alcohol use was similar but did not change with age and increased among drivers recruited at night. Cannabis was more likely to be detected at younger ages and cocaine was associated with night driving.

Alcohol use before driving has decreased over the last decade; however, the consumption of other illegal drugs seems to have increased. The pattern of illegal psychoactive substance observed is similar to that declared in surveys of the general population of adults.

Words: 291

Key words: Psychoactive substance use; drivers; oral fluid; breath test; screening test; epidemiology. 


\section{INTRODUCTION}

Road traffic accidents constitute an important health burden worldwide. This problem was highlighted by a report from the WHO in 2004. It is estimated to be increasing, particularly in low-income countries [1]. To overcome this burden, in Europe a target of significantly reducing road traffic fatalities ( $50 \%$ fewer deaths on the road in the period 2002-2010) was set [2]. In order to attain it, various initiatives have been implemented. As one of the major factors affecting driving performance is the consumption of psychoactive substances, in the EU there was a need to assess the prevalence of driving under the influence of alcohol and other psychoactive drugs and medicines. The EU funded DRUID project (Driving Under the Influence of Drugs, Alcohol and Medicines) was initiated in 2006 [3], and included the use of roadside drug testing equipment by the police. Spain was a partner in the DRUID project and a survey among drivers was performed in 2008 [4].

To continue monitoring the situation and in order to assess actions taken, a new survey was conducted in 2013 [5] and repeated in 2015, within the Spanish Research Plan on Road Safety and Mobility 2013-2016 [6]; the so-called "Estudio sobre la prevalencia del consumo de sustancias psicoactivas en conductores de vehiculos de España-EDAP"[Prevalence study of psychoactive substances use among Spanish drivers].

From the law enforcement point of view, it would be necessary to consider whether roadside screen tests for substances other than alcohol, have an adequate validity. On-site tests for oral fluid are considered an effective and non-invasive method to detect drug-use, but some problems of sensitivity for substances still remain $[7,8]$

The aim of the present study was to assess the prevalence of alcohol and illicit drugs use, and selected psychoactive substances beyond those tested at the roadside, through analyses of oral fluid and breathtests in a representative nationwide sample of the general population of drivers in Spain. A secondary aim was to assess sensitivity and specificity of the roadside device used (Dräger DrugTest ${ }^{\circledR}$ ).

\section{METHODS}

An observational study among drivers of motor vehicles (bicycles and vehicles over 3,500 $\mathrm{kg}$ were excluded) on public roads in Spain was conducted in 2015. To obtain a representative sample nationwide, a multistage method was applied to select 128 police control sites. In the first stage, the country was divided in four Areas ("Cantábrica", "Norte", "Mediterránea", and "Sur"). In a second step, within each of these four areas, four population stratums according to cities' population sizes (less than 10,000 inhabitants, 10,00099,999 inhabitants, 100,000-499,999, and 500,000 inhabitants and over) were defined, in each of which two sectors, one urban the other interurban, were considered; in each combination of stratum and sector, four zones were randomly selected, resulting in a total of 32 zones. The third step involved choosing four roadside 
check points in each zone according to predefined selection criteria for each sector (urban/interurban), allowing the selection of 128 roadside check points, or police control sites. Finally, in each one of them, the number of police control actions and the quota of drivers to be recruited per action was determined based on the population size. Control actions were planned in four spring (interurban) and four autumn (urban) weeks. Four periods were selected within those weeks, considering different days of the week and hours of the day (a) Monday-Friday from 7:00 to 23:59 h (weekdays); (b) Tuesday-Friday from 0:00 to 6:59 $\mathrm{h}$ (weeknights); (c) Saturday, Sunday and holidays from 7:00 to 23:59 h (weekend days); (d) Saturday, Sunday, Monday and holidays from 0:00 to 6:59 h (weekend nights).

\subsection{Driver recruitment and data collection}

Drivers of either Spanish or foreign nationality were recruited by a traffic police officer at the police control site when space was available for a vehicle to be stopped at the site. According to Spanish legislation, participation in roadside police controls is mandatory; thus participation rate was $100 \%$. After informing the driver about the aim of the control and samples needed, oral fluid samples were obtained and then drivers were submitted to an alcohol breath test. Two samples of oral fluid (approximately $1 \mathrm{~mL}$ each) were taken using specific devices (Quantisal ${ }^{\circledR}$, Alere Toxicology Plc, UK); one of them screened at roadside for opiates, amphetamines, cocaine and metabolites, and cannabinoids, using the Dräger DrugTest ${ }^{\circledR} 5000$ (Dräger Safety AG \& Co, Lübeck, Germany) [9]. If a positive result was obtained for at least one substance, the second sample was sent for laboratory confirmation, in a special container at a temperature between $2^{\circ} \mathrm{C}$ and $8^{\circ} \mathrm{C}$, within 36 hours of collection. After oral fluid collection and the alcohol breath test had been done, a research questionnaire, with a unique identifying code, was completed by traffic police officers. The following information was collected: (i) sociodemographic data (gender, age, nationality), (ii) driving patterns (type of vehicle and the driving license class), and (iii) date and time of the day. Results of the on-site oral fluid sample test (positive or negative to each of the five screened substances) and alcohol breath test (in $\mathrm{mg} / \mathrm{L}$ ) were also recorded. When the second oral fluid sample needed to be analyzed, identifying stickers were used to trace results anonymously.

\subsection{Toxicological aspects}

At the roadside, the Dräger DrugTest device was used for drug screening using the following cut-off concentrations: opiates (morphine), $20 \mathrm{ng} / \mathrm{mL}$; amphetamines (D-amphetamine), $50 \mathrm{ng} / \mathrm{mL}$; methamphetamine (D-methamphetamine), $35 \mathrm{ng} / \mathrm{mL}$; cocaine (cocaine), $20 \mathrm{ng} / \mathrm{mL}$; THC (Delta-9-THC), $25 \mathrm{ng} / \mathrm{mL}$. Benzodiazepines were not monitored as in 2013 the Spanish government decided not to maintain them in road drug testing.

Alcohol concentration in exhaled air was measured in $\mathrm{mg}$ alcohol/liter by the Dräger Alcotest ${ }^{\circledR}$ (Alcotest 7110 MKIII). The breath test was considered positive if the concentration was $>0.05 \mathrm{mg} / \mathrm{L}$. 
The quantitative drug confirmation test in oral fluid for 26 substances (Table 1 ) was performed after a solid phase extraction procedure. Extracts were analyzed by liquid chromatography coupled to tandem mass spectrometry (UHPLC-MS/MS). The concentration was calculated in neat oral fluid by using the average dilution factor specified by the manufacturer (1/4). All oral fluid samples were analyzed in the same laboratory (accredited following the ISO17025 by the national accreditation body -ENAC [Entidad Nacional de Acreditación (Spanish National Accreditation Body)]- for this kind of analyses).

Assessment of agreement between roadside (on-site drug screening test) and laboratory tests was only possible among drivers for whom a second oral fluid sample was sent for laboratory confirmation, meaning they had at least one oral fluid positive result at roadside. For these drivers, sensitivity and specificity was calculated overall and for each of the four drug classes screened at roadside: Cannabis, Opioids, Cocaine and Amphetamines, allowing a partial appraisal of drug use screening at the roadside. Sensitivity was defined as the ability of the test to identify correctly those who have the disease; while specificity as the ability of the test to identify correctly those who do not have the disease.

\subsection{Data analysis}

An anonymized database was built including questionnaire data as well as laboratory confirmation results. All the variables in the database were examined for accuracy of data entry and missing values. Special attention was given to correctness of linking between questionnaire and laboratory information. Positive results for the 26 different substances analyzed were grouped into: Cannabis; Opiates/Opioids (morphine, codeine, 6-monoacetylmorphine, methadone); Benzodiazepines (alprazolam, clobazam, clonazepam, flunitrazepam, lorazepam, diazepam, nordiazepam, oxazepam); Cocaine (cocaine, benzoylecgonine); Amphetamine like stimulants/designer drugs (Amphetamine, MDA, Methamphetamine, MDMA, MDEA); Ketamine and Z-Pharmaceuticals (zopiclone, zolpidem). When only pharmaceutical drugs were detected in a sample the result was considered negative for alcohol or illegal substances.

Table 1. Substances and cut-off concentrations in laboratory confirmation samples

\begin{tabular}{|l|c|}
\hline \multicolumn{1}{|c|}{ Substance } & $\begin{array}{c}\text { Cut-off concentration } \\
\text { oral fluid }(\mathbf{n g} / \mathbf{m L})\end{array}$ \\
\hline 6-monoacetylmorphine & 0.8 \\
\hline alprazolam & 1 \\
\hline amphetamine & 1.9 \\
\hline benzoylecgonine & 1.6 \\
\hline clobazam & 5 \\
\hline clonazepam & 1 \\
\hline cocaine & 1.6 \\
\hline codeine & 1.9 \\
\hline$\Delta^{9}$-THC & 0.4 \\
\hline
\end{tabular}




\begin{tabular}{|l|c|}
\hline diazepam & 5 \\
\hline flunitrazepam & 1 \\
\hline ketamine & 1.9 \\
\hline lorazepam & 10 \\
\hline LSD & 1.9 \\
\hline MDA & 1.9 \\
\hline MDEA & 1.9 \\
\hline MDMA & 1.9 \\
\hline mescaline & 10 \\
\hline methadone & 1.9 \\
\hline methamphetamine & 1.9 \\
\hline morphine & 1.9 \\
\hline nitrazepam & 5 \\
\hline nordiazepam & 1 \\
\hline oxazepam & 5 \\
\hline zolpidem & 1 \\
\hline zopiclone & 1 \\
\hline
\end{tabular}

Percentages of positives cases for alcohol and each substance group are presented with their 95\% confidence interval $(\mathrm{Cl})$. Description of continuous variables includes their mean and standard deviation (SD).

Comparisons between groups were carried out using $\chi^{2}$ and Fisher's exact tests for categorical variables and Student's t-test and analyses of variance (ANOVA) for continuous variables. Logistic regression analyses were used to evaluate the association between positive drug findings and age, sex (male/female), road type (urban/interurban), and period of the week (weekdays, weeknights, weekend days, weekend nights) both overall and separately for alcohol, cannabis and cocaine. Age and gender were included in the regression model even if not significant. Significance level was set at $p \leq 0.05$ with two-tailed tests. The statistical package SPSS 22.0 was used for all analyses.

\section{RESULTS}

\subsection{Characteristics of drivers involved in the study}

A total of 2744 drivers were included in the study, $77.8 \%$ were males. Their mean age was 37.5 years [standard deviation (SD) 12.0; range 18-87]. Most of the participants were Spanish (88.7\%) and drove a car (87.7\%). Sex differences were observed in nationality, probably related to the fact that no Moroccan women were included; also the great majority of females drove a private car and females were more likely to be stopped on urban roads (Table 2 ). 
Table 2. Socio-demographic characteristics of drivers included in the study.

\begin{tabular}{|c|c|c|c|c|c|}
\hline & & $\begin{array}{c}\text { Males } \\
\text { n (\%) } \\
2135(77.8)\end{array}$ & $\begin{array}{c}\text { Females } \\
n(\%) \\
564(20.6)\end{array}$ & $\begin{array}{l}\text { Total }^{1} \\
\text { n (\%) } \\
2744\end{array}$ & $p$ \\
\hline Mean age $(\text { mean } \pm S D)^{2}$ & & $37.7 \pm 12.3$ & $37 \pm 10.9$ & $37.5 \pm 12.0$ & \\
\hline Age groups (years) ${ }^{2}$ & $\begin{array}{l}18-24 \\
25-34 \\
35-49 \\
\geq 50\end{array}$ & $\begin{array}{r}298(14) \\
659(30.9) \\
803(37.6) \\
366(17.1)\end{array}$ & $\begin{array}{r}64(11.3) \\
198(35.1) \\
218(38.7) \\
82(14.5)\end{array}$ & $\begin{array}{r}376(13.7) \\
865(31.5) \\
1036(37.8) \\
456(16.6)\end{array}$ & \\
\hline Nationality & $\begin{array}{l}\text { Spain } \\
\text { European Union } \\
\text { Other European countries } \\
\text { Latin America } \\
\text { Morocco } \\
\text { Other countries } \\
\text { No answer/do not know }\end{array}$ & $\begin{array}{r}1875(87.8) \\
114(5.3) \\
11(0.5) \\
61(2.9) \\
31(1.5) \\
24(1.1) \\
0(0) \\
\end{array}$ & $\begin{array}{r}501(88.8) \\
31(5.5) \\
4(0.7) \\
11(2.0) \\
0(0) \\
5(0.9) \\
1(0.2) \\
\end{array}$ & $\begin{array}{r}2406(87.7) \\
149(5.4) \\
18(0.7) \\
74(2.7) \\
33(1.2) \\
31(1.1) \\
1(0.3) \\
\end{array}$ & $* *$ \\
\hline Type of vehicle & $\begin{array}{l}\text { Private car } \\
\text { Motorized Bike } \\
\text { Motorcycle } \\
\text { Other } \\
\text { Non-registered vehicles }\end{array}$ & $\begin{array}{r}1827(85.6) \\
27(1.3) \\
82(3.8) \\
193(9) \\
10(0.5)\end{array}$ & $\begin{array}{r}541(95.9) \\
3(0.5) \\
7(1.2) \\
11(2) \\
10(1.8) \\
\end{array}$ & $\begin{array}{r}2408(87.7) \\
30(1.1) \\
91(3.3) \\
205(7.5) \\
10(0.4)\end{array}$ & $* *$ \\
\hline Area & $\begin{array}{l}\text { Cantabrian } \\
\text { Mediterranean } \\
\text { North } \\
\text { South }\end{array}$ & $\begin{array}{l}525(24.6) \\
440(20.6) \\
585(27.4) \\
585(27.4) \\
\end{array}$ & $\begin{array}{l}163(28.9) \\
114(20.2) \\
147(26.1) \\
140(24.8) \\
\end{array}$ & $\begin{array}{r}696(25.4) \\
577(21) \\
740(27) \\
731(26.6) \\
\end{array}$ & \\
\hline Type of road & $\begin{array}{l}\text { Interurban } \\
\text { Urban }\end{array}$ & $\begin{array}{r}1169(54.8) \\
966(45.2)\end{array}$ & $\begin{array}{l}281(49.8) \\
283(50.2)\end{array}$ & $\begin{array}{l}1463(53.3) \\
1281(46.7)\end{array}$ & $*$ \\
\hline
\end{tabular}

\subsection{Prevalence of positive cases and their characteristics}

The roadside ethanol breath test gave positive results for 72 drivers (2.6\%). Roadside screening tests detected a total of 353 drivers (12.9\%) with a positive result for at least one of the tested substances (including alcohol). Of these, $7.8 \%$ were positive for cannabis, $3.5 \%$ for cocaine, $1.5 \%$ for amphetamine-like stimulants/designer drugs, and $0.5 \%$ for opiates/methadone.

Considering alcohol at roadside and laboratory confirmation results for the rest of substances, after excluding those subjects $(n=5)$ with only a pharmaceutical drug, $11.6 \%$ of the drivers were positive for at least one of the substances assessed (Figure 1). Overall 7.7\% tested positive for only one substance, $3.1 \%$ were positive for a combination of substances (alcohol not included), and only $0.8 \%$ gave positive results for alcohol and another substance (Table 3). Cannabis, cocaine and alcohol (separately) were the substances that were most frequently found $(7.5 \%, 4.7 \%$ and $2.6 \%$, respectively). Positive cases for amphetamine-like stimulants/designer drugs were also common (1.3\%), followed by benzodiazepines, opiates/methadone $(90 \%$ of which were positive for 6-monoacetylmorphine) and ketamine (no Z-drugs were detected), all of them with rates lower than $1 \%$. 
Prevalence of positive cases for any substance (whether alone or combined with alcohol) was higher in males $(13.4 \%)$ than in females $(5.1 \%)$. When considering different substances separately, differences by gender were observed for alcohol, cannabis and cocaine, being more likely in males than in females (Table 3). Also, the likelihood of finding a driver positive for some substance decreased with age $(p<0.0001)$ (Table 4$)$. The highest prevalence of positive results for cannabis (15.2\%) was found in the younger age group (18-24 years), whereas the highest for cocaine (7.4\%) was found in the group aged 25 to 34 years. In turn, driving under the influence of any drug was more likely at night (both on weekdays and at weekends) than during daytime $(p=0.001)$. This pattern was also observed for alcohol $(p<0.0001)$ and cocaine $(p=0.002)$. Regarding the type of road, it was more likely to find drivers positive for both alcohol and other substances in urban settings $(p<0.001)$. Likewise, when considering different substances separately, alcohol and cannabis were also more frequently observed in urban settings ( $<0.0001$ and $p=0.029$, respectively). 
Figure 1. Alcohol- and illegal drug- positive cases in Spanish drivers according to cut-off concentrations as set out in Table 1.

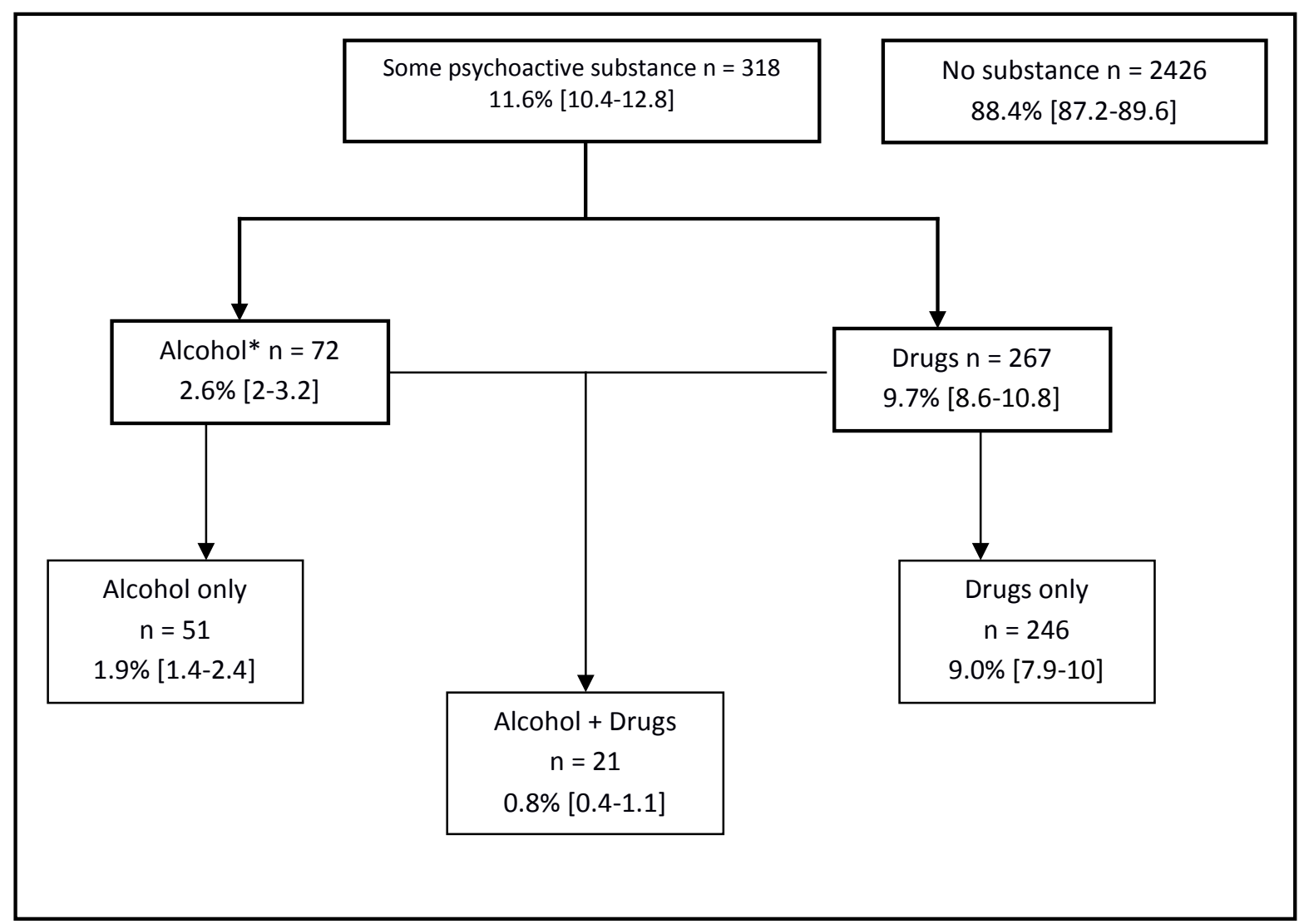

*Alcohol positive test if $>0.05 \mathrm{mg} / \mathrm{L}$ 
Table 3. Percentage distribution of positive cases according to substance groups and gender.

\begin{tabular}{|c|c|c|c|c|c|c|c|}
\hline & \multicolumn{4}{|c|}{ Gender } & & & \multirow{3}{*}{$p$} \\
\hline & \multicolumn{2}{|c|}{$\begin{array}{c}\text { Male } \\
n=2135\end{array}$} & \multicolumn{2}{|c|}{$\begin{array}{l}\text { Female } \\
n=564\end{array}$} & \multicolumn{2}{|c|}{$\begin{array}{c}\text { Total }^{\S} \\
n=2744\end{array}$} & \\
\hline & $\mathrm{n}$ & $\%\left[95 \% \mathrm{Cl}^{\dagger}\right]$ & $\mathrm{n}$ & $\%[95 \% \mathrm{Cl}]$ & $\mathrm{n}$ & $\%[95 \% \mathrm{Cl}]$ & \\
\hline Alcohol >0.05mg/l & 64 & $3.0[2.3-3.7]$ & 8 & $1.4[0.4-2.4]$ & 72 & $2.6[2-3.2]$ & * \\
\hline Cannabis & 186 & 8.7 [7.5-9.9] & 17 & $3.0[1.6-4.4]$ & 205 & $7.5[6.5-8.5]$ & $* *$ \\
\hline Cocaine and cocaine derivatives & 118 & $5.5[4.6-6.5]$ & 10 & $1.8[0.7-2.9]$ & 128 & $4.7[3.9-5.5]$ & $* *$ \\
\hline Amphetaminic stimulants/designer drugs & 33 & $1.5[1-2.1]$ & 3 & $0.5[0-1.1]$ & 36 & $1.3[0.9-1.7]$ & \\
\hline Benzodiazepines & 15 & $0.7[0.3-1.1]$ & 0 & 0 & 15 & $0.7[0.4-1.0]$ & \\
\hline Opiates/Methadone & 9 & $0.4[0.1-0.7]$ & 1 & $0.2[0-0.5]$ & 10 & $0.4[0.2-0.6]$ & \\
\hline Ketamine & 6 & $0.3[0.1-0.5]$ & 0 & 0 & 6 & $0.2[0-0.4]$ & \\
\hline Only one substance (alcohol included) & 186 & $8.7[7.5-9.9]$ & 23 & $4.1[2.4-5.7]$ & 211 & $7.7[6.7-8.7]$ & \\
\hline Several substances (without alcohol) & 82 & $3.8[3-4.7]$ & 4 & $0.7[0-1.4]$ & 86 & $3.1[2.5-3.8]$ & \\
\hline Alcohol + some substance & 19 & 0.9 [0.5-1.3] & 2 & $0.4[0-0.8]$ & 21 & $0.8[0.4-1.1]$ & \\
\hline No (alcohol or illegal) substances & 1848 & $86.6[85.1-88]$ & 535 & 94.9 [93-96.7] & 2426 & 88.4 [87.2-89.6] & \\
\hline
\end{tabular}

${ }^{\$}$ Including all cases (also the 45 drivers without gender information).

${ }^{\dagger} \mathrm{Cl}=$ confidence interval.

$* p<0.05 \quad{ }^{* *} p<0.0001$ 
Table 4. Percentage distribution of positive results to the most frequently detected substances according to age, type of road and period of the week.

\begin{tabular}{|c|c|c|c|c|c|c|c|c|c|c|c|}
\hline & & \multicolumn{10}{|c|}{ Substances } \\
\hline & & \multicolumn{2}{|l|}{ Any } & \multicolumn{2}{|c|}{ Alcohol } & \multicolumn{2}{|c|}{ Cannabis } & \multicolumn{2}{|c|}{ Cocaine } & \multicolumn{2}{|c|}{$\begin{array}{c}\text { Amphetaminic } \\
\text { stimulants/designer } \\
\text { drugs }\end{array}$} \\
\hline & & $n(\%)$ & $p$ & $n(\%)$ & $p$ & n (\%) & $p$ & n (\%) & $p$ & n (\%) & $p$ \\
\hline Age (years) & $\begin{array}{l}18-24(n=376) \\
25-34(n=865) \\
35-49(n=1036) \\
>50(n=456)\end{array}$ & $\begin{array}{c}66(17.6) \\
131(15.1) \\
96(9.3) \\
24(5.3)\end{array}$ & $* *$ & $\begin{array}{l}11(2.9) \\
19(2.2) \\
26(2,5) \\
15(3.3)\end{array}$ & & $\begin{array}{c}57(15.2) \\
98(11.3) \\
44(4.2) \\
6(1.3)\end{array}$ & $* *$ & $\begin{array}{l}17(4.5) \\
64(7.4) \\
38(3.7) \\
8(1.8)\end{array}$ & $* *$ & $\begin{array}{c}4(1.1) \\
22(2.5) \\
10(2.0) \\
0(0)\end{array}$ & $*$ \\
\hline Type of road & $\begin{array}{l}\text { Urban }(n=1281) \\
\text { Interurban }(n=1463)\end{array}$ & $\begin{array}{c}182(14.2) \\
136(9.3)\end{array}$ & $* *$ & $\begin{array}{l}49(3.8) \\
23(1.6)\end{array}$ & $* *$ & $\begin{array}{l}111(8.7) \\
94(6.4)\end{array}$ & $*$ & $\begin{array}{l}69(5.4) \\
59(4.0)\end{array}$ & & $\begin{array}{l}15(1.2) \\
21(1.4)\end{array}$ & \\
\hline Period of the week & $\begin{array}{l}\text { Weekdays }(n=835) \\
\text { Weeknights }(n=666) \\
\text { Weekend days }(n=705) \\
\text { Weekend nights }(n=538)\end{array}$ & $\begin{array}{c}79(9.5) \\
92(13.8) \\
66(9.4) \\
81(15.1)\end{array}$ & * & $\begin{array}{l}6(0.7) \\
30(4.5) \\
10(1.4) \\
26(4.8)\end{array}$ & $* *$ & $\begin{array}{l}57(6.8) \\
51(7.7) \\
51(7.2) \\
46(8.6)\end{array}$ & & $\begin{array}{l}25(3.0) \\
43(6.5) \\
26(3.7) \\
34(6.3)\end{array}$ & $*$ & $\begin{array}{l}6(0.7) \\
11(1.7) \\
9(1.3) \\
10(1.9)\end{array}$ & \\
\hline
\end{tabular}

\footnotetext{
$* p<0.05 \quad * * p<0.0001$
} 
Logistic regression analysis showed that the likelihood of finding a driver positive for any substance decreased with age (Odds Ratio $(\mathrm{OR})=0.96,95 \% \mathrm{Cl}=0.95-0.97$ ), was higher among men $(\mathrm{OR}=3.03,95 \% \mathrm{Cl}=2.03-4.51)$ and among drivers stopped on urban roads (OR=1.73, $95 \% \mathrm{Cl}=1.35-2.20)$. The likelihood of finding a driver positive for alcohol was associated with being male $(O R=2.16,95 \% \mathrm{Cl}=1.02-4.56)$, driving on urban roads $(\mathrm{OR}=2.45,95 \% \mathrm{Cl}=1.47-4.06)$ and driving at night: both during the week $(\mathrm{OR}=6.29 ; 95 \% \mathrm{Cl}=2.58-15.33)$ and at weekends $(O R=7.31,95 \% \mathrm{Cl}=2.96-18.07)$. The likelihood of detecting cannabis was higher among the youngest age group $(\mathrm{OR}=0.91,95 \% \mathrm{Cl}=0.89-0.94)$, whereas cocaine positive results were associated with driving on weeknights $(\mathrm{OR}=3.27,95 \% \mathrm{Cl}=1.69-6.36)$ and on weekend nights (OR=3.0, 95\% Cl=1.5-6.0)(Table 5). 
Table 5. Logistic regression analysis: significant variables associated with cases found positive for any substance, alcohol, cannabis and cocaine.

\begin{tabular}{|c|c|c|c|c|}
\hline & Any substance & Alcohol & Cannabis & Cocaine \\
\hline & OR† $\dagger(95 \% \mathrm{Cl}) \dagger$ & OR $(95 \% \mathrm{Cl})$ & OR $(95 \% \mathrm{Cl})$ & OR (95\% Cl) \\
\hline Age (years) & $0.96(0.95-0.97)^{* *}$ & $1.01(0.99-1.03)$ & $0.91(0.89-0.94)^{* *}$ & $1.02(0.99-1.05)$ \\
\hline Gender (ref. female) & & & & \\
\hline Men & $3.03(2.03-4.51)^{* *}$ & $2.16(1.02-4.56)^{*}$ & $1.59(0.64-4.00)$ & $1.43(0.60-3.37)$ \\
\hline $\begin{array}{r}\text { Type of road (ref. interurban) } \\
\text { Urban }\end{array}$ & $1.73(1.35-2.20)^{* *}$ & $2.45(1.47-4.06)^{*}$ & & \\
\hline $\begin{array}{l}\text { Period of the week } \\
\text { (ref. weekdays (7:00 - 23:59h)) }\end{array}$ & & & & \\
\hline $\begin{array}{l}\text { Weeknights }(0: 00-6: 59 h) \\
\text { Weekend days }(7: 00-23: 59 h) \\
\text { Weekend nights }(0: 00-6: 59 h)\end{array}$ & $\begin{array}{l}1.27(0.91-1.76) \\
0.88(0.62-1.25) \\
1.35(0.96-1.90)\end{array}$ & $\begin{array}{l}6.29(2.58-5.33)^{* *} \\
1.94(0.70-5.39) \\
7.31(2.968 .07)^{* *}\end{array}$ & & $\begin{array}{c}3.27(1.69-6.36)^{* *} \\
1.47(0.75-2.90) \\
3.0(1.50-6.0)^{*}\end{array}$ \\
\hline$\chi^{2} \mathrm{H}-\mathrm{L} \S$ & $8.27(0.49)$ & $11.79(0.16)$ & $10.74(0.22)$ & $12.07(0.15)$ \\
\hline
\end{tabular}

$* p<0.05 \quad * * \mathrm{p}<0.0001$

$\dagger \mathrm{OR}=$ odds ratio estimate; $\mathrm{Cl}=$ confidence interval.

$\S \chi^{2} \mathrm{H}-\mathrm{L}$ : Hosmer-Lemeshow test ( $p$-value). 


\section{3.- Sensitivity and specificity.-}

The level of agreement overall between the two tests (on-site drug testing vs. confirmatory analysis by LCMS) for the four analyzed substances was $88.4 \%$. Taking into account all drugs (295 drivers*4 tests), 52 (18\%) false positive and 85 (29\%) false negative results were detected.

The best agreement with Dräger DrugTest ${ }^{\circledR}$ findings and laboratory confirmation was found for cannabis (sensitivity of $90 \%$, and specificity of $77 \%$ ), followed by cocaine (sensitivity of $68 \%$ and specificity of $96 \%$ ). The specificity figure for cannabis means that some of the positive results for cannabis on-site were not confirmed by laboratory tests $(23 \%)$, whereas the sensitivity for cocaine means that laboratory tests gave positive results which screening tests had not detected previously (false negatives) (32\%)(Table 6). The Dräger DrugTest ${ }^{\circledR}$ on-site device provided the lowest sensitivity (47\%) and the highest specificity (97\%) for detection of Opiates/Methadone, which were the substances less frequently detected.

Table 6. Agreement level of on-site drug screening test and laboratory test results for each group of analyzed substances.

\begin{tabular}{|c|c|c|c|c|c|}
\hline & & \multicolumn{4}{|c|}{ On-site drug test results } \\
\hline & & Positive & Negative & & \\
\hline & Laboratory test results & $\mathbf{n}$ & $\mathbf{n}$ & Sensitivity & Specificity \\
\hline \multirow[t]{2}{*}{ Cannabis } & Positive & 185 & 20 & \multirow{2}{*}{0.90} & \multirow{2}{*}{0.77} \\
\hline & Negative & 21 & 69 & & \\
\hline \multirow[t]{2}{*}{ Opiates/Methadone } & Positive & 8 & 9 & \multirow{2}{*}{0.47} & \multirow{2}{*}{0.97} \\
\hline & Negative & 7 & 271 & & \\
\hline \multirow[t]{2}{*}{ Cocaine and cocaine derivatives } & Positive & 87 & 41 & \multirow{2}{*}{0.68} & \multirow{2}{*}{0.96} \\
\hline & Negative & 7 & 160 & & \\
\hline \multirow[t]{2}{*}{ Amphetaminic stimulants/designer drugs } & Positive & 21 & 15 & \multirow{2}{*}{0.58} & \multirow{2}{*}{0.93} \\
\hline & Negative & 17 & 242 & & \\
\hline
\end{tabular}




\section{DISCUSSION}

This roadside study with a representative nationwide sample of the general population of drivers in Spain found that a significant percentage of drivers (11.6\%) had used substances that may affect driving performance. In four percent (4\%) of drivers two or more substances were detected. The most common substances were cannabis, cocaine and alcohol, in that order. Males were more likely than females to use any substance overall, as well as alcohol. Drivers tested in urban roads were more likely to use any substance, and alcohol. The only factor associated with positive tests for cannabis was age, whereas for cocaine, drivers tested at weeknights and weekend nights were more likely to be positive. Driving at night was also associated with positive results for alcohol. Agreement between roadside screening results and laboratory confirmation for subjects with at least one positive result at roadside was higher for cannabis and cocaine.

As pointed out previously, the present study represents a continuation in Spain of the monitoring by the European Union's research project on Driving Under the Influence of Drugs, Alcohol and Medicines, known as the DRUID project. Compared to the previous edition in 2013, in which roadside screening detected 12.1\% of drivers positive for some psychoactive drug [5], two years later (2015), after weighting results (to make them comparable), the figure has remained stable at $12.3 \%$. However, as a significant decrease in positive cases for alcohol (from $3.4 \%$ in 2013 to $2.6 \%$ in 2015 ; $p<0.05$ ) was observed, positive cases screened at roadside for other substances increased (8.0 [7.0-8.9] to 10.7 [9.5-11.8]; $p<0.001)$ [10].

When comparing the prevalence of psychoactive substances among drivers with that of the general population in Spain, we need to take into account two factors: first, reports from surveys are selfreported data, and second, the time periods considered were different. EDAP provided objective prevalence at a very specific time point linked to driving, while the biannual national survey EDADES (Encuesta sobre Alcohol y Drogas en España) [11], including a broad sample of the Spanish noninstitutionalized general population aged 15 to $64(2013, N=23,136)$, provided self-reported information for lifetime, last year and last month, as well as last month daily use for substances used more frequently. EDAP point prevalence for cannabis was in the range of EDADES-2013 last month prevalence (7\%), much higher than the $2 \%$ daily use registered for the general population aged 15 to 64 that year. Regarding cocaine the $4.7 \%$ registered among drivers was higher than EDADES prevalence last year $(2 \%)$ and last month (1\%). For other substances (e.g.: amphetamines, heroin), EDADES yielded results under $1 \%$ for last year as well as last month prevalence, more in accordance with EDAP figures. Concerning alcohol it is not possible to make relevant comparisons as, although alcohol drinking is embedded in Spanish culture, drivers have for many years been informed about the alcohol drinking driving legislation. Nevertheless, we can compare EDAP results with the $10 \%$ of daily alcohol use during the last 30 days, and with EDADES binge drinking reported by $15.5 \%$ of the population, and drunkenness reporting by $19 \%$ of individuals aged 
15-64 years old, EDAP results being much lower (2.6\%). Overall, except for alcohol, which is the most commonly used substance among the general population, other substances had a similar or slightly higher frequency pattern among drivers included in this study.

Likewise, when comparing results with prevalence data in Europe, it is significant that in Europe, cannabis use prevalence is the highest of illegal substances, about five times higher than any other substance. [12] Also in Europe use of all drugs is generally higher among males. Besides, Spain together with the Netherlands and the United Kingdom reported last year prevalence of cocaine use among young adults of $3 \%$ or more. Cocaine use in Europe is mainly recreational, and similarly to our results, the highest use is during weekends and holidays. In the European DRUID-2008, results from Spanish drivers were among the highest in the study [4].

Although oral fluid drug concentrations should parallel those in blood, recent studies in populations of drivers with low prevalence of drug consumption show that oral fluid samples do not accurately reflect blood concentrations [13]. Regarding validity of screen tests, we are able to assess sensitivity and specificity for substances tested by the device Dräger DrugTest ${ }^{\circledR}$, but only among persons who were positive for at least one substance. In contrast to some studies indicating that further improvement is needed to enhance the sensitivity for detection of THC in oral fluid [14], in the present study, the Dräger DrugTest $^{R} 5000$ provided the highest sensitivity for detection of cannabis $(90 \%)$, with a lower figure for specificity (77\%). However, in the present study the percentage of false positives in cocaine was $4 \%$ (specificity of $96 \%$, with a sensitivity of $68 \%$ ), data that contrasts to the $11 \%$ found in another study [14]. A low sensitivity of the roadside screen test may be related to the fact that screening cut-off concentrations are higher than those from the certified laboratory, and this may explain cocaine results, especially the false negatives (32\%). Conversely, the low specificity of cannabis screen test is more difficult to elucidate, though it may be related to its high sensitivity. This is relevant, as similarly to the general population, cocaine and cannabis are the most common illegal substances among drivers. Globally the discussion on sensitivity and specificity of the testing device in our report is biased by the fact that only those samples testing positive for a given substance were retested for the rest of the panel in the confirmatory laboratory. Therefore our estimates are based on samples testing positive for drugs and do not refer to a population of samples with mixed positive and negative oral fluids. Nevertheless this early discussion does not preclude the debate on the reliability of these testing devices. The performance of the analytical device for cocaine was not particularly good.

Concerning psychoactive non-illicit drugs, it was not possible to verify if they were used under prescription. This could be of relevance as non-prescribed use of psychoactive prescription drugs is common in subjects suspected of drug-impaired driving $[15,16]$. Quantification of these other drugs allow for an overall picture of drug use among drivers, beyond the most common illegal substances. 


\section{Limitations}

Some limitations need to be mentioned. First of all we need to point out difficulties in fieldwork, affecting both recruitment and organizational aspects (e.g.: one big city in the Mediterranean area could not be included; a few questionnaires (9) from positive laboratory samples could not be retrieved, nor were confirmatory samples obtained for 6 positive questionnaires). Furthermore, data collected didn't allow weighting for traffic intensity using the same procedure employed in previous editions, and consequently only roadside screening results have been weighted with traffic intensity at each check point, to be able to make a comparison. Also, traffic police officers recruited drivers according to space availability at police check points, but we cannot discard that riskier drivers had been selected. Furthermore, the overall performance of the Dräger DrugTest ${ }^{\circledR}$ as a screening tool needs to be taken into account to adequately appraise the situation. Additionally, contrary to other countries [17, 18], in this study cut-off concentrations were those provided by the testing device in the absence of Spanish legislation defining safety margins for psychoactive drugs.

Drivers in Spain display a pattern of psychoactive substance use similar to that observed in the general population of adults, except for the case of alcohol which is clearly lower. In fact, alcohol use while driving seems to have diminished over the last decade, probably in response to strong prevention strategies. The dangers related to the use of other substances while driving is not yet well recognized by Spanish drivers. Roadside tests for psychoactive substances need improvement if they are to constitute an adequate means for enforcing effective vigilance. 


\section{REFERENCES}

[1] WHO. Global status report on road safety 2015. Geneva, World Health Organization, 2015. http://www.who.int/violence injury prevention/road safety status/2015/en/

[2] COMMISSION OF THE EUROPEAN COMMUNITIES WHITE PAPER European transport policy for 2010: time to decide. Brussels, 2001. https://ec.europa.eu/transport/sites/transport/files/themes/strategies/doc/2001 white paper/lb com 200 10370 en.pdf (accessed June 2017)

[3] DRUID (Driving under the Influence of Drugs, Alcohol and Medicines). European Commission. Federal Highway Research Institute. 2006. http://www.druid-project.eu/Druid/EN/Home/home node.html

[4] T. Gómez-Talegón, I. Fierro, J.C. González-Luque, M. Colás, M. López-Rivadulla, F. Javier Álvarez, Prevalence of psychoactive substances, alcohol, illicit drugs, and medicines, in Spanish drivers: a roadside study, Forensic Sci. Int. 223 (2012) 106-113.

[5] I. Fierro, J.C. González-Luque, M. Seguí-Gómez, F.J. Álvarez, Alcohol and drug use by Spanish drivers: Comparison of two cross-sectional road-side surveys (2008-9/2013), Int. J. Drug Policy. 26 (2015) 794-797.

[6] Dirección General de Tráfico. PLAN DE INVESTIGACIÓN EN SEGURIDAD VIAL Y MOVILIDAD 2013-2016. Ministerio del Interior. Madrid, 2013. http://www.dgt.es/Galerias/seguridad-vial/investigacion/planinvestigacion/Plan-de-Investigacion-DGT-2014.pdf

[7] B.K. Logan, A.L. Mohr, S.K. Talpins, Detection and prevalence of drug use in arrested drivers using the Dräger Drug Test 5000 and Affiniton DrugWipe oral fluid drug screening devices, J. Anal. Toxicol.38 (2014) 444-450.

[8] F. Musshoff, E.G. Hokamp, U. Bott, B. Madea, Performance evaluation of on-site oral fluid drug screening devices in normal police procedure in Germany, Forensic Sci. Int. 238 (2014) 120-124.

[9] S.W. Toennes, G.F. Kauert, S. Steinmeyer, M.R. Moeller, Driving under the influence of drugs --evaluation of analytical data of drugs in oral fluid, serum and urine, and correlation with impairment symptoms, Forensic Sci. Int. 152 (2005) 149-155.

[10] M.J. Herrero, A Domingo-Salvany, R. de la Torre, Trends in drug consumption at the roadside in Spain (2008-2015). Data in Brief, submitted.

[11] Observatorio Español de la Droga y las Toxicomanías. Informe 2015. Alcohol, tabaco y drogas ilegales en España. Ministerio de Sanidad, Servicios Sociales e Igualdad. Madrid. http://www.pnsd.msssi.gob.es/profesionales/sistemas/nformacion/informesEstadisticas/pdf/INFORME 2015. $\underline{\mathrm{pdf}}$

[12] Observatorio Europeo de las Drogas y las Toxicomanías (2016), Informe Europeo sobre Drogas 2016: Tendencias y novedades, Oficina de Publicaciones de la Unión Europea, Luxemburgo. http://www.emcdda.europa.eu/system/files/publications/2637/TDAT16001ESN.pdf

[13] H. Gjerde, K. Langel, D. Favretto, A.G. Verstraete, Detection of illicit drugs in oral fluid from drivers as biomarker for drugs in blood, Forensic Sci. Int. 256 (2015) 42-45.

[14] A.G. Verstraete, Oral fluid testing for driving under the influence of drugs: history, recent progress and remaining challenges, Forensic Sci. Int. 150 (2005) 143-150. 
[15] K. Karjalainen, J. Haukka, T. Lintonen, M. Joukamaa, P. Lillsunde, The use of psychoactive prescription drugs among DUI suspects, Drug Alcohol Depend. 155 (2015) 215-221.

[16] M. Tjäderborn, A.K. Jönsson, T.Z. Sandström, J. Ahlner, S. Hägg, Non-prescribed use of psychoactive prescription drugs among drug-impaired drivers in Sweden, Drug Alcohol Depend. 161 (2016) 77-85.

[17] L. Kristoffersen, D.H. Strand, V.H. Liane, V. Vindenes, I.F. Tvete, M. Aldrin, Determination of safety margins for whole blood concentrations of alcohol and nineteen drugs in driving under the influence cases, Forensic Sci. Int. 259 (2016) 119-126.

[18] M.C. Strand, H. Gjerde, J. Mørland, Driving under the influence of non-alcohol drugs--An update. Part II: Experimental studies, Forensic Sci. Rev. 28 (2016) 79-101. 